Published by Al-Nahrain College of Medicine P-ISSN 1681-6579

E-ISSN 2224-4719

Email: iraqijms@colmed-alnahrain.edu.iq http://www.colmed-alnahrain.edu.iq http://www.iraqijms.net

\title{
Brachial Artery Diameter as a Predictor of Endothelial Dysfunction in Sickle Cell Disease
}

\author{
Hasna O. Al-Janabi ${ }^{1} P h D$, Wasan I. Al-Saadi ${ }^{2}$ FIBMS, Farqad B. Hamdani ${ }^{1}$ PhD, Waseem F. Al- \\ Tameemi ${ }^{3}$ CABMS, FICMS, FIBMS
}

${ }^{1}$ Dept. of Physiology \& Medical Physics, ${ }^{2}$ Dept. of Surgery, ${ }^{3}$ Dept. of Medicine, College of Medicine, Al-Nahrain University, Baghdad, Iraq

\begin{abstract}
Background Sickle cell disease is hematological disease that affect the endothelial function. The hemoglobinopathy in this disease triggers erythrocyte polymerization and the sickling process leads to vascular occlusion, tissue hypoxia and subsequent reperfusion injury, thus inducing inflammation and endothelial injury.

Objective To assess the value of brachial artery diameter measurement as a predictor of the state of endothelium in sickled individuals.

Methods Thirty patients with sickle cell disease ( 15 females and 15 males) with a mean age of ( $27.0 \pm 8.9 \mathrm{yr}$ ) and 30 healthy controls ( 18 females and 12 males) with a mean age of ( $29.7 \pm 9.1 \mathrm{yr}$ ) participated in the study. Assessment of endothelial function done by studying physiological parameters, which included flow-mediated dilatation and endothelial-independent dilatation of the brachial artery depending on the measurement of the diameter of the blood vessel.

Results Endothelial independent dilatation was significantly lower in sickle cell disease patients (21.71 \pm 6.96$)$ in comparison with that of the control group $(26.81 \pm 6.31)$ despite the findings that both base line brachial artery diameter and intima media thickness were not significantly different between both groups.

Conclusion Brachial artery diameter assessment is a useful noninvasive predictor of endothelial dysfunction in patients with sickle cell disease. The reproducibility of the test in addition to its low cost and being free of biological hazards makes it optimum for assessing the state of the endothelium and may be used to monitor the response to treatment.

Keywords Sickle cell disease, flow-mediated dilatation, endothelial-independent dilatation, brachial artery diameter.
\end{abstract}

DOI: $10.22578 / \mathrm{IJMS}$.14.4.8

List of abbreviation: ED: Endothelial dysfunction, EID: Endothelial-independent dilatation, FMD: Flow-mediated dilatation, $\mathrm{Hb}$ : Hemoglobin, NTG = Nitroglycerin, NO = Nitrous oxide, SCD = Sickle cell anemia

\section{Introduction}

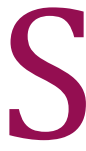
ickle cell disease (SCD) is an inherited disorder in which, the adult hemoglobin $(\mathrm{HbA})$ is replaced by sickle hemoglobin (HbS) due to a single base-pair change. This alteration leads to chronic hemolytic anemia, pain, and later to organ failure ${ }^{(1,2)}$. HBS usually polymerizes when deoxygenated to form a gelatinous network of fibrous polymers that stiffen the erythrocyte membrane, increase viscosity, and cause dehydration due to potassium leakage and calcium influx. These changes also produce the sickle RBCs ${ }^{(3)}$.

The endothelium, the largest organ in the body, is the inner most layer of the blood vessels. It senses mechanical stimuli, such as pressure and shear stress, and, hormonal stimuli, such as vasoactive substances. In 
response, it releases agents that regulate vasomotor function, trigger inflammatory processes, and affect hemostasis (4). The vascular endothelium is an active paracrine, endocrine, and autocrine organ that is indispensable for the regulation of vascular tone and the maintenance of vascular homeostasis ${ }^{(5,6)}$. The endothelium also plays a pivotal role in regulating blood flow, generating an active antithrombotic surface that facilitates transit of plasma and cellular constituents throughout the vasculature. Thus, dysfunction or damage to the endothelium causes a vasodilator response of the blood vessels ${ }^{(7)}$. Several vasomotor tests have been proposed to assess the state of the endothelium. These tests are based on the concept that certain stimuli trigger the release of nitrous oxide (NO) from the endothelium to mediate vascular relaxation. Quantitative coronary artery diameter assessment at angiography before and after infusion of vasoactive substances and strain-gauge venous impedance plethysmography for the forearm arteries are considered as sensitive tools. However, these tests are rather invasive procedures and reproducibility is questionable ${ }^{(5)}$.

An alternative method for assessment of endothelial function is the measurement of flow mediated dilation (FMD) of the brachial artery in response to increased shear stress during hyperemia, using high-resolution ultrasound; the technique was introduced in 1992 by Celermajer and associates as a noninvasive endothelial function test ${ }^{(8)}$. Accordingly, it was demonstrated that flowdependent dilation of the radial and brachial arteries is largely sustained by NO synthase ${ }^{(9)}$. This stimulus provokes the endothelium to release nitrous oxide (NO) with subsequent vasodilation that can be imaged and quantified as an index of vasomotor function. This technique is attractive because it is noninvasive and allows repeated measurements and therefore, provides a valuable "read-out" of vascular NO availability. The amount of vasodilatation is directly proportional to the amount of NO released by the endothelium and this allows us to evaluate endothelial function. The increase in flow and vasodilatation is measured by high-resolution ultrasonography of the brachial artery ${ }^{(10)}$.

The aim of this study was to assess the value of brachial artery diameter measurement as a predictor of the state of endothelium in sickled individuals.

\section{Methods}

The study was conducted at Ultrasound Unit at Al-Nahrain College of Medicine after being approved by the Research Ethical Committee at Al-Nahrain College of Medicine. A written consent was obtained from each participant after explaining the details of the procedure. The patients were recruited from Hematology Unit of Al-Imamein Al-Kadhimein Medical City, Department of Inherited Blood Diseases in AlKarama Teaching Hospital, and the National Center for hematology ( $\mathrm{NCH}$ ). All patients were previewed and examined by specialist or consultant hematologist to define eligibility to be enrolled in this study at the aforementioned centers. Patients were confirmed to have SCD clinically and by laboratory measures. The examination, assessment and the investigations needed for the research were done in the Central Laboratory of Al-Imamein Al-Kadhimein Medical City and in Al-Nahrain College of Medicine.

The study had been conducted from April 2013 to November 2014. A total of 60 subjects were included in this study; thirty of them (15 females and 15 males) were patients with homozygous sickle cell disease proved by the result of hemoglobin electrophoresis, and 30 (18 males and 12 females) were apparently healthy individuals with normal blood film findings and were considered as control, the latter subjects included college staff and medical personnel. Both the patients and the controls were of a comparable age group.

The inclusion criteria for the patients group were a homozygous $\mathrm{Hb}$ SS disease patient proved on clinical and laboratory basis aged 15 
years old or above with $\mathrm{Hb}>6 \mathrm{~g} / \mathrm{dL}$. Those SCA patients with severe anemia $(\mathrm{Hb} \leq 6 \mathrm{~g} / \mathrm{dl})$, recent crises within the last week or recent blood transfusion in the last 4 weeks were excluded from the study. Other exclusion criteria were pregnancy, intake of tonic supplement within the last week or on any statin drug within the last four weeks, patients with significant cardiac disease and/or ECG abnormalities. In addition, other conditions that may independently affect endothelial function, i.e., diabetes mellitus, cigarette smoking, and hypertension (diastolic blood pressure $>90 \mathrm{mmHg}$ ) were not included in the study.

Detailed history and general physical examinations were carried out for each individual included in this study, an assessment of vital signs, and systemic examination performed to assess any possible complications. The height and the weight of the patients were estimated to calculate the body mass index (BMI)

For each individual included in this study, the physiological parameters of the endothelial function assessment were done after an overnight fasting.

The ultrasound study was performed with a multi-frequency (5-13 $\mathrm{MHz}$ ) linear array probe LOGIQ P6 PRO, GE healthcare, Austria. All ultrasound scans were performed by a single radiologist experienced in vascular sonography. The ultrasound assessment was performed in the morning between 8 and 10 A.M.

The brachial artery diameter was assessed using Gray scale and spectral doppler sonography (Figure 1).

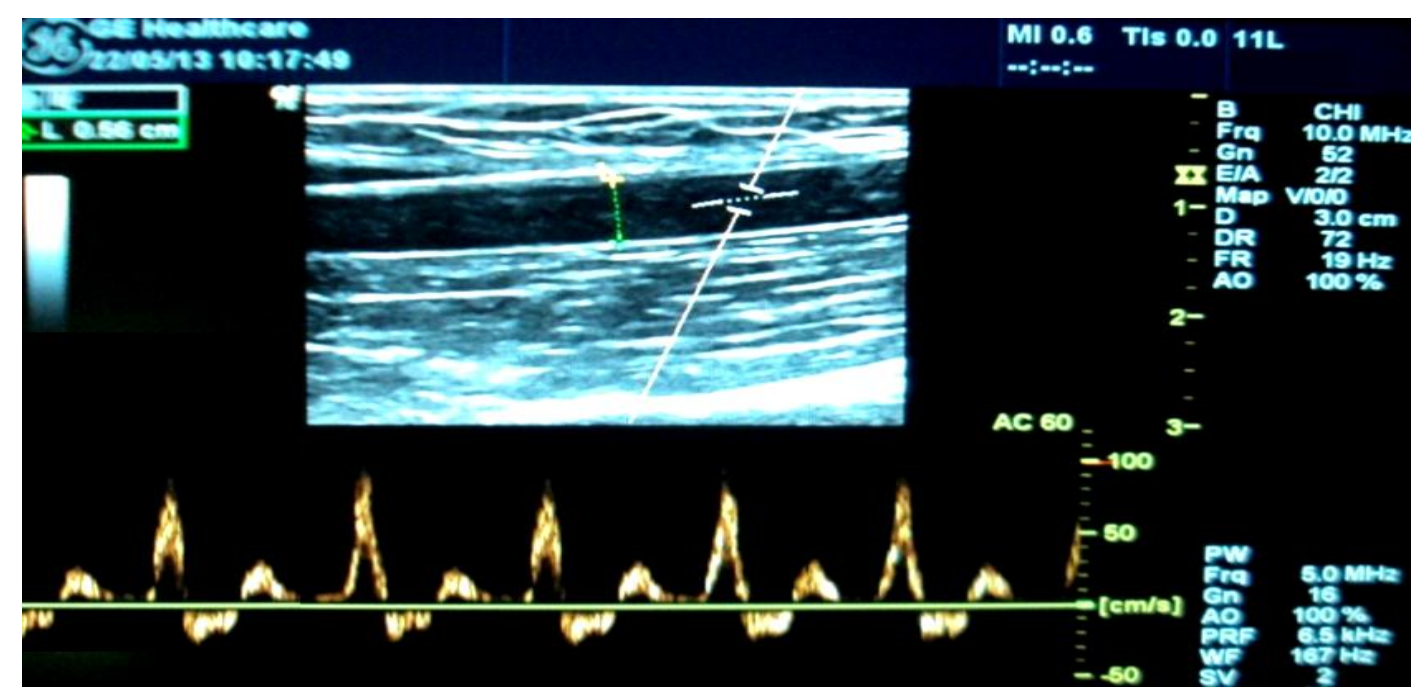

Figure 1. The ultrasound assessment of the diameter of the brachial artery

The patient/subject was asked to rest in a supine position for at least $10 \mathrm{~min}$ (for blood pressure stabilization), the right brachial artery was imaged $2-5 \mathrm{~cm}$ above the elbow. A segment with clear anterior and posterior intimal interfaces between the lumen and the vessel wall was selected for continuous gray scale imaging in longitudinal plane. During image acquisition, anatomical landmarks such as veins and fascial planes were noted to help maintain the same image of the artery throughout the study and the scanned area was marked to measure the same segment of brachial artery repeatedly i.e. at rest, after reactive hyperemia, and after administration of nitroglycerin (NTG). The Brachial artery diameter was measured at the same time in the cardiac cycle, the latter was achieved by using the spectral Doppler to define the image of interest at the peak systolic time. At the sites where luminal areas were measured, the intima-media thickness (IMT) was defined as 
the distance between the blood-intima interface (the intimal leading edge) and the media-adventitia interface (the leading edge of the next bright layer). All recorded values represent the average of three consecutive measurements

A baseline rest image was acquired; the vessel diameter was measured with ultrasonic calipers from the leading edge of the anterior wall to the leading edge of the posterior wall of the brachial artery. Thereafter, arterial occlusion was created by sphygmomanometer cuff inflation to at least $50 \mathrm{mmHg}$ above systolic pressure for $5 \mathrm{~min}$ to occlude arterial inflow.

The same measurements were repeated within 1 min after cuff deflation to assess FMD. Brachial artery diameter percent change was calculated and recorded as the FMD of the patient. The variability of the diameter measurement was minimized by calculating the average derived from 3 diameter measurements determined along the longitudinal segment of brachial artery. At least $10 \mathrm{~min}$ of rest is needed after reactive hyperemia (i.e., FMD) before another image is acquired to reflect the re-established baseline condition. Then a single dose of $(0.4 \mathrm{mg})$ of NTG sublingual tablet had been given for 5 minutes to determine the maximum obtainable vasodilator response, and to serve as a measure of endothelium-independent vasodilation (EID) reflecting vascular smooth muscle function. After $5 \mathrm{~min}$ the NTG tablet was discarded and the same protocol for measurement of the diameter of the brachial artery was used as mentioned previously.

The changes after both interventions i.e. after stress and after NTG were expressed as percentage change from pretreatment value. Percentage increase in lumen diameter during post ischemic hyperemia as compared to basal lumen diameter, labeled as flow-mediated dilation; a marker of endothelium dependent dilation, is calculated as the maximum change in diameter from baseline, expressed as a percentage according to following equation:-
FMD $=(d 2-d 1) \times 100 / d 1$; where $d 1$ is the brachial artery baseline diameter and $\mathrm{d} 2$ is brachial artery diameter at $1 \mathrm{~min}$ of cuff release. The percentage increase in lumen diameter after administration of NTG tablet as compared to basal lumen diameter was labeled as NTG\%. As a marker of endothelium independent dilation, is calculated as the maximum change from baseline, expressed as a percentage change in diameter, using the same equation to assess the EID, as follow: $E I D=(d 3-d 1) \times 100 / d 1$; where $d 1$ is the brachial artery baseline diameter and $\mathrm{d} 3$ is brachial artery diameter after 5 min of administration of NTG tablet.

Analysis of data was carried out using the available statistical package of SPSS-22 (Statistical Packages for Social Sciences- version 22). Data were presented in simple measures of frequency, percentage, mean, standard deviation, and range (minimum-maximum values). The significance of difference of different means (quantitative data) were tested using Students-t-test for difference between two independent means. The significance of difference of different percentages (qualitative data) were tested using Pearson Chi-square test $\left(\mathrm{X}^{2}\right.$-test) with application of Yate's correction or Fisher exact test whenever applicable. Statistical significance was considered whenever the $P$ value for the test of significance was equal or less than 0.05 .

\section{Results}

The study enrolled 30 patients with SCD (age range $15-50$ years, mean $\pm S D=27.0 \pm 8.9$ years) and 30 apparently healthy subjects (age range 18-49 years, mean $\pm S D=29.7 \pm 9.1$ ). Significant difference was found between the patients group and the control group regarding the BMI $\left(22.9 \pm 4.0 \mathrm{~kg} / \mathrm{m}^{2}\right.$ for the SCD patients versus $26.1 \pm 4.7 \mathrm{~kg} / \mathrm{m}^{2}$ of the control group). Categorization of BMI was done according to the WHO criteria into 4 groups: Underweight (BMI: < 18.5), Normal (BMI: 18.5-24.9), Overweight (BMI: 25-29.9) and Obese (BMI: $\geq$ 
30). In general, SCD patients appear to have lower $\mathrm{BMI}$ when compared to the control subjects $(P=0.006)$, and even when they were categorized $(P=0.022)$. Table 1 summarizes the distribution of $\mathrm{BMI}$ of both studied groups.

Table 1. Body mass index of the sickle cell disease patients and control subjects

\begin{tabular}{cccccc}
\hline \multirow{2}{*}{ BMI $\left(\mathrm{kg} / \mathrm{m}^{\mathbf{2}}\right)$} & \multicolumn{2}{c}{ SCD patients } & \multicolumn{2}{c}{ Control subjects } & \multirow{2}{*}{ P value } \\
& No. & $\%$ & No. & \% & \\
\hline Underweight (<18.5) & 4 & 13.3 & 1 & 3.3 & \\
Normal (18.5 - 24.9) & 20 & 66.7 & 12 & 40.0 & \multirow{2}{*}{0.022} \\
Overweight (25 - 29.9) & 4 & 13.3 & 13 & 43.3 & \\
Obese ( $\geq$ 30) & 2 & 6.7 & 4 & 13.3 & \\
\hline Mean BMI + SD & \multicolumn{2}{c}{$22.9 \pm 4.0$} & \multicolumn{2}{c}{$26.1 \pm 4.7$} & 0.006 \\
\hline
\end{tabular}

Concerning the FMD, no significant difference was found in value of FMD\% of the brachial artery when comparing the SCD patients and the control (13.02 vs. 15.91 respectively), however, the EID\% in SCD patients (mean= 21.71) was significantly lower $(P<0.05)$ than that of controls (mean $=26.81$ ) (table 2 ). On the other hand, no significant differences was found in the basal brachial artery diameter and intima media thickness between both groups (Table 2).

Table 2. Vascular physiological parameters for SCD patients and the control subjects

\begin{tabular}{cccc}
\hline $\begin{array}{c}\text { Physiological } \\
\text { Parameters }\end{array}$ & $\begin{array}{c}\text { SCD patients } \\
\text { (Mean } \pm \text { SD) }\end{array}$ & $\begin{array}{c}\text { Control subjects } \\
\text { (Mean } \pm \text { SD) }\end{array}$ & P value \\
\hline FMD\% & $13.02 \pm 4.59$ & $15.91 \pm 6.60$ & 0.054 \\
EID\% & $21.71 \pm 6.96$ & $26.81 \pm 6.31$ & $0.004^{*}$ \\
BAD $(\mathrm{mm})$ & $3.41 \pm 0.52$ & $3.55 \pm 0.43$ & 0.27 \\
BAIMT $(\mathrm{mm})$ & $0.33 \pm 0.06$ & $0.35 \pm 0.07$ & 0.49
\end{tabular}

BAD = brachial artery diameter, BAIMT = brachial artery intima media thickness, FMD = flow mediated dilatation, EID $=$ endothelial independent dilatation, $*$ = significant difference

Positive correlation had been demonstrated between the FMD and EID in SCD patients $(r=$ $0.752 ; p=0.0001$, figure2). However both parameters were negatively correlated with the base line diameter of the brachial artery in SCD patients (Figures 3,4).

\section{Discussion}

Sickle cell disease (SCD) is the commonest structural $\mathrm{Hb}$ variant; the outlook for patients with SCD continues to be poor. Today there is no doubt that general survival is improving with more medical care and improvement of environmental and social factor ${ }^{(11)}$.

This study had revealed that SCD patients have lower body mass index as compared to controls. This finding is in agreement with many previous studies ${ }^{(12,13)}$, this finding could be a consequence of the increased resting energy expenditure caused by the increased erythropoietic and cardiac activities ${ }^{(14)}$, or it could reflect the greater increase in height than weight usually seen in adolescents with SCD ${ }^{(11-15)}$. 


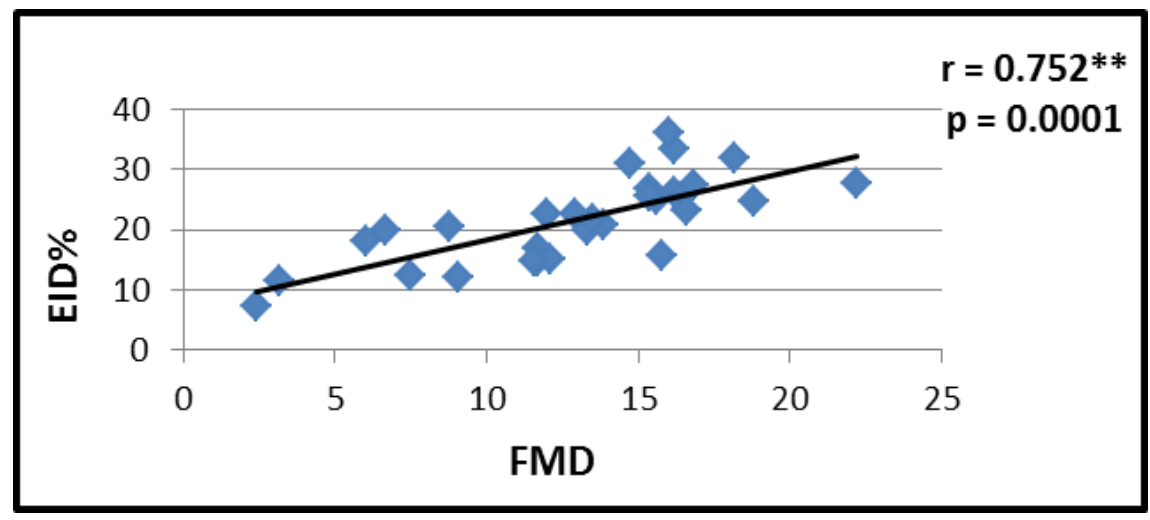

Figure 2. Correlation between flow mediated dilatation and endothelial-independent dilatation

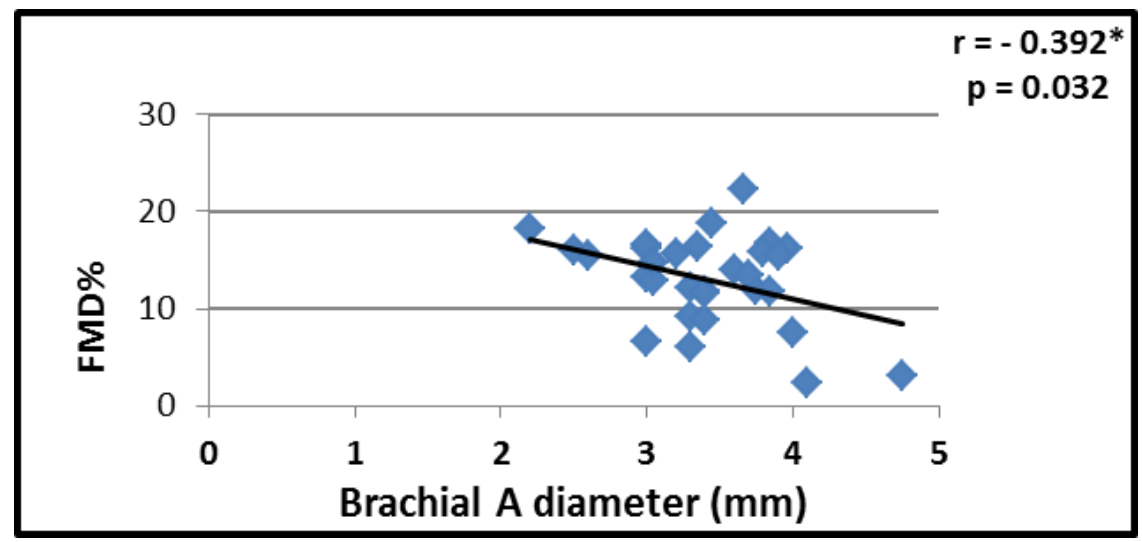

Figure 3. Correlation between flow mediated dilatation and brachial artery diameter in sickle cell disease patients

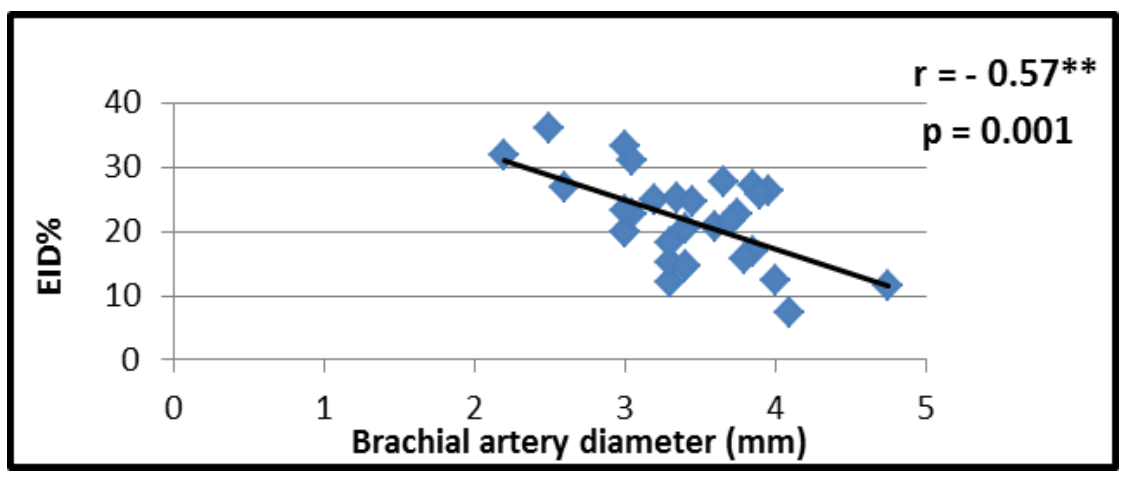

Figure 4. Correlation between endothelial- independent dilatation and brachial artery diameter in sickle cell disease patients

Decline in endothelial function was observed with increasing duration of symptoms and vaso-occlusive crisis/year in SCD cases. While others had mentioned that FMD was decreased or impaired in SCD patients in steady states ${ }^{(18-}$ 20). One possible explanation for the insignificant difference in FMD could be due to fact that the control subjects enrolled in this 
study had have higher BMI than patients. Other possible explanation is that the impaired FMD in the patients suggest failure of muscular arteries to adjust their internal diameter in response to mechanical stimulation. Overall, these results strongly suggest that systemic arteries in patients with SCD fail to adjust appropriately to chronic or acute increases in wall shear stress, which reflects mechanical forces exerted on endothelial cells.

Flow-mediated and nitroglycerin-induced dilation were both impaired in SCD compared to controls. The impaired response raises the possibility that there is a generalized loss of the bioavailability of nitrous oxide or impairment of the function of vascular smooth muscle to response to nitrous oxide, which is produced either by the endothelium or by sublingual nitrate administration.

This study showed no difference in brachial artery diameter and IMT in patients and control, this is in concordance with Eberhardt, $20033^{(18)}$ and Belhassen, et al $2001^{(21)}$. Interestingly, baseline brachial artery diameter was similar in the patients and controls. It had been shown that, at a normal state, a sustained increment in the wall shear stress induces NO dependent increase in arterial diameter that normalizes wall shear stress regardless of blood flow. Therefore, in SCD, failure of vessels to adjust their diameter to wall shear stress changes probably reflects an impairment in the basal or stimulated release of nitrous oxide ${ }^{(21)}$.

The present study conclusion was brachial artery diameter assessment is a useful noninvasive predictor of endothelial dysfunction in patients with sickle cell disease. The reproducibility of the test in addition to its low cost and being free of biological hazards makes it optimum for assessing the state of the endothelium and may be used to monitor the response to treatment.

\section{Acknowledgments}

Special thanks to the physicians and medical personnel at Hematology Unit of Al-Imamein
Al-Kadhimein Medical City, Department of Inherited Blood Diseases at Al-Karama Teaching Hospital, and the National Center for Hematology Diseases and Researches for their valuable help in referring the patients.

\section{Author contribution}

Dr. Al-Janabi collects the data and interprets the results, Dr. Al-Saadi did the Doppler study, Dr. Hamdan interprets the results and finalizes the writing the article and Dr. Al-Tammemi examined the patients and interprets the results.

\section{Conflict of interest}

The author declares that they have no competing interests.

\section{Funding}

None.

\section{References}

1. Kumar V, Abbas AK, Fausto $N$, et al. Robbins and Cotran pathologic basis of disease. $8^{\text {th }}$ ed. Philadelphia: Saunders Elsevier; 2010. P. 639-75.

2. Higgs DR, and Wood WG. Genetic complexity in sickle cell disease. PNAS. 2008; 105(33): 11595-6.

3. Voet D, Voet JG, Pratt CW. Fundamentals of Biochemistry. $4^{\text {th }}$ ed. New York: John Wiley \& Sons; 2013. p. 183, 184, 189, 194.

4. Schiffrin EL, Schiffrin EL. Role of endothelin-1 in hypertension. Curr Hypertens Reports. 2003; 5(2): 144-8.

5. Tousoulis D, Antoniades C, Stefanadis C. Evaluating endothelial function in humans: a guide to invasive and non-invasive techniques. Heart. 2005; 91(4): 5538.

6. Anderson TJ. Arterial stiffness or endothelial dysfunction as a surrogate marker of vascular risk. Can J Cardiol. 2006; 22(Suppl B): 72B-80B.

7. Cines DB, Pollak ES, Buck CA, et al. Endothelial cells in physiology and in the pathophysiology of vascular disorders Review article. Blood. 1998; 91(10): 352761.

8. Celermajer DS, Sorensen KE, Gooch VM, et al. Noninvasive detection of endothelial dysfunction in children and adults at risk of atherosclerosis. Lancet. 1992; 340(8828): 1111-5.

9. Joannides R, Haefeli WE, Linder L. et al. Nitric oxide is responsible for flow-dependent dilatation of human peripheral conduit arteries in vivo. Circulation. 1995; 91(5): 1314-9. 
10. Corretti MC, Anderson TJ, Benjamin EJ, et al. Guidelines for the ultrasound assessment of endothelial-dependent flow-mediated vasodilation of the brachial artery: a report of the International Brachial Artery Reactivity Task Force. J Am Coll Cardiol. 2002; 39(2): 257-65.

11. Khalid KE, Mohammed $\mathrm{HI}$, Daoud $\mathrm{OH}$, et al. Evaluation of biochemical changes in homozygous sickle cell disease patients in western Sudan. Al Neelain Med J. 2012, 2(6): 24-36.

12. Odetunde OI, Chinawa JM, Achigbu KI, et al. Body mass index and other anthropometric variables in children with sickle cell anemia. Pak J Med Sci. 2016; 32(2): 341-6.

13. Oguanobi NI, Onwubere BJC, Ibegbulam OG, et al. Arterial blood pressure in adult Nigerians with sickle cell anemia. J Cardiol. 2010, 56: 326-31.

14. Lamarre $\mathrm{Y}$, Lalanne-Mistrih $\mathrm{ML}$, Romana $\mathrm{M}$, et al. Male gender, increased blood viscosity, body mass index and triglyceride levels are independently associated with systemic relative hypertension in sickle cell anemia. PLoS ONE. 2013; 8(6): e66004. doi: 10.1371/journal.pone.0066004.

15. Ozigbo CJ, Nkanginieme KEO. Body mass index and sexual maturation in adolescent patients with sickle cell anaemia. Nig J Paediatr. 2003; 30(2): 39-44.

16. Raghuwanshi Pk, Raghuvanshi SS. Vascular endothelial dysfunction in sickle cell disease by brachial artery flow mediated dilatation. Asian J Of Med Sci. 2014; 5(3): 105-7.
17. Zawar SD, Vyawahare MA, Nerkar M, et al. Noninvasive detection of endothelial dysfunction in sickle cell disease by doppler ultrasonography. JAPI. 2005; 53: 677-80.

18. Eberhardt RT, McMahon L, Duffy SJ, et al. Sickle cell anemia is associated with reduced nitric oxide bioactivity in peripheral conduit and resistance vessels. Am J Hematol. 2003; 74: 104-11.

19. Blum A, Yeganeh, S., Peleg A, et al. Endothelial function in patients with sickle cell anemia during and after sickle cell crises. J Thromb Thrombolysis. 2005; 19(2): 83-6.

20. Mushemi-Blake S. Characteristics of cardiovascular dysfunction and pulmonary hypertension in patients with sickle cell disease. http://kclpure.kcl.ac.uk/portal/2013.

21. Belhassen L, Pelle G., Sediame S., et al. Clinical observation, intervention and therapeutic trials. Endothelial dysfunction in patients with sickle cell disease is related to selective impairment of shear stress-mediated vasodilation. Blood. 2001; 97(6): 1584-9.

\section{Correspondence to Dr. Hassna O. Al-Janabi \\ E-mail: hassna.abd.ha@gmail.com \\ Received 22 ${ }^{\text {nd }}$ June 2015: Accepted $20^{\text {th }}$ Oct. 2016}

